\title{
Prevalance of Depression among Patients with Chronic Kidney Disease.
}

\author{
Reya Thomas ${ }^{1}$, Sourya Acharya ${ }^{2}$, Samarth Shukla ${ }^{3}$ \\ 1. Primary Researcher, MBBS \\ 2. Professor, Dept. Of Medicine \\ 3. Professor, Dept of Pathology JN Medical College DMIMS University Sawangi Wardha
}

\begin{abstract}
:
Objective: Depression is a common psychiatric illness in patients with chronic kidney disease (CKD). It has been shown to affect morbidity \& mortality in these patients. This study was done to determine the prevalence of depression in CKD patients.

Method: This cross sectional study was done in DMIMS university, Acharya Vinobha Bhave Rural Hospital located in central india is a tertiary hospital. A self administered Zung questionnaire was administered. This questionnaire has 20 questions with an individual scoring to each question. Individuals with a total score of 50 are considered depressed \& score above 70 indicates severe depression.
\end{abstract}

Results: Thirty (30) patients of CKD with or without dialysis \& 14 controls were interviewed. There were 12 (85\%) males \& $2(15 \%)$ females. All were age matched. The prevalence of depression among CKD patients was $96.66 \%$ while for control group was $5 \%(P<0.00)$. Further analysis revealed that $C K D$ patients who were not on dialysis were more depressed than the patients who were on dialysis treatment. The mean Zung score in pre dialysis patients was $61.47 \pm 3.95$ versus ESRD patients on dialysis which was $56.30 \pm 3.79(P<0.001)$.

Conclusion: Depression is highly prevalent among our patients with CKD. We opine that along with other management of CKD symptoms of depression should be targeted \& should be considered for treatment.

Key Words: $C K D$, depression, Zung depression scale, pre-dialysis.

\section{Introduction}

Psychiatric disorders are common among patients with chronic kidney diseases \& these include depression, dementia, psychosis, anxiety, personality disorders \& substance abuse. ${ }^{(1)}$ Depression is the most common psychiatric problem in patients with end stage renal disease (ESRD) ${ }^{(1-3)}$. The prevalence of depression in CKD patients have varied widely in different studies, in different population using different assessment tools. Prevalence rate is high as $30 \%$ have been reported in some studies. ${ }^{(2-4)}$

Depression is characterised by both cognitive \& somatic features. The somatic characteristic of depression are very similar to symptoms of uraemia such as anorexia, sleep disturbances, fatigue, gastrointestinal disorders. ${ }^{(1-3)}$ Symptoms suggestive of depression include: depressed mood most of the time, loss of interest or pleasure in most of the activities for most of the time. Co-morbid depression impacts negatively on life in CKD \& improved detection \& intervention (pharmacological \& non- pharmacological) will improves its outcomes. In this study, we evaluate the frequency of symptoms of depression in CKD patients \& also determine the relationship between treatment category (dialysis $\&$ pre-dialysis).

\section{Materials \& Methods}

This was a cross sectional study of patients with CKD attending the medicine outpatient clinic of Jawaharlal Nehru Medical College Sawangi (meghe),teaching hospital (AVBRH). Approval was given by the health research \& ethical committee of the institution, consecutive CKD patients who agreed to participate in the study were recruited. The control group consisted of healthy age matched individuals of the relatives of patients \& few staff. Demographic \& clinical data were documented.

We used the Zung self rating depression scale (ZSDS) which is widely validated 20-weighted item questionnaire including questions to identify the presence of affective,psychological \& somatic symptoms associated with depression. The cut off for defining depression using the ZSDS is 50. The score of 60-69 is indicative of moderate depression while $\geq 70$ is severe depression. ${ }^{(5)}$ The maximum score that could be achieved is 80 . The ZSDS questionnaire was translated into hindi \& marathi language for patients who could not speak English. The patients with end stage renal disease (ESRD) on dialysis were compared with those with pre dialysis CKD (Stages 3-5 but not on dialysis) \&CKD patients with control. 


\section{Data Analysis}

Continuous variables are presented as mean \pm standard deviation (SD) \& compared using student $T$ test. Categorical variables are presented as proportions \& compared using Yates corrected $\mathrm{X}^{2}$ test. Multivariable analysis was used to determine risk factors associated with depression. P value $<0.05$ is regarded as being statistically significant.

\section{Observations and Results}

\section{Results}

Table 1: Comparison of demographic characteristics and ZSDS parameters in CKD patients and controls

\begin{tabular}{|l|l|l|l|}
\hline Clinical Parameters & CKD Patients $\mathrm{n}=30$ & Controls $\mathrm{n}=20$ & $\mathrm{p}$-value \\
\hline Mean Age(Years) $\pm \mathrm{SD}$ & $48.66 \pm 15.61$ & $32.40 \pm 12.50$ & $0.000, \mathrm{~S}$ \\
\hline $\begin{array}{l}\text { Number of Male/Female } \\
\text { Subjects }\end{array}$ & $24 / 6$ & $12 / 2$ & $0.69, \mathrm{NS}$ \\
\hline Mean Zung Score \pm SD & $59.23 \pm 4.62$ & $37.85 \pm 6.46$ & $0.000, \mathrm{~S}$ \\
\hline $\begin{array}{l}\text { No of patients with } \\
\text { depression }\end{array}$ & $29(96.66 \%)$ & $1(5 \%)$ & $0.000, \mathrm{~S}$ \\
\hline
\end{tabular}

Graph 1: Distribution of CKD patients and controls with regards to depression

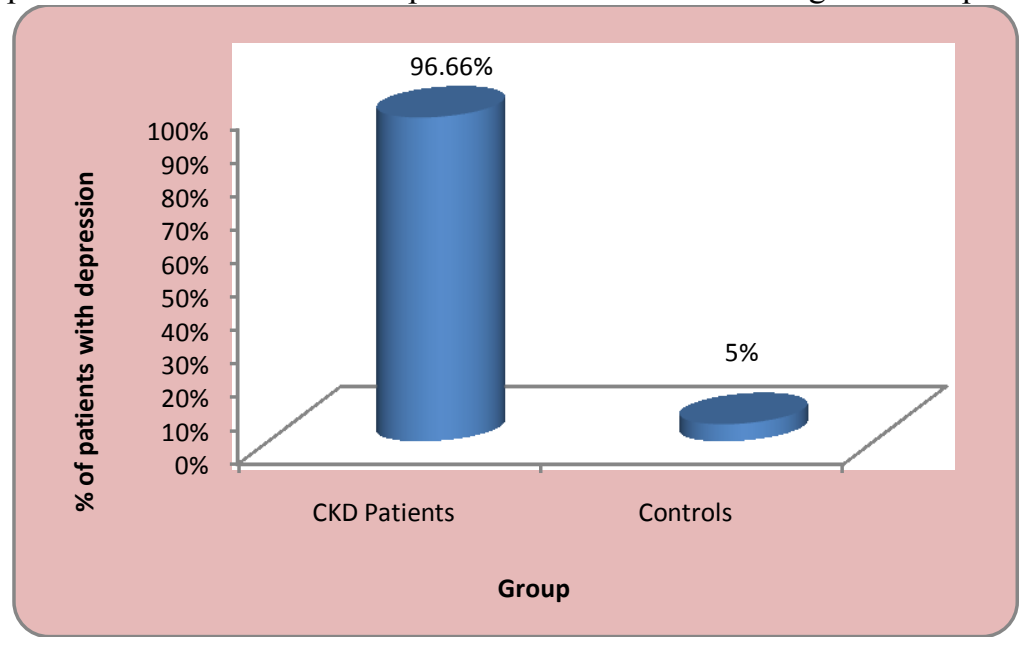

We studied a total of 30 patients of CKD \& 14 controls. The controls were age \& sex matched. There were 12 males $(85 \%)$ \& 2 females $(15 \%)$ in control group. The mean age of CKD patients \& controls were similar $(48.66 \pm 15.61 \& 32.40 \pm 12.50)$.

Mean Zung score between the CKD patients $(59.23 \pm 4.62)$ controls $(37.85 \pm 6.46)$ were statistically significant $(\mathrm{P}<0.00)$. Number of patients with depression (prevalence) in CKD was $96.66 \%$ versus control group was only $5 \%$ which was again statistically significant.

Table 2: Comparison of demographic characteristics and ZSDS parameters in pre-dialysis and ESRD patients

\begin{tabular}{|l|l|l|l|}
\hline Clinical Parameters & $\begin{array}{l}\text { Pre-dialysis patients } \\
\mathrm{n}=17\end{array}$ & ESRD Patients $\mathrm{n}=13$ & $\mathrm{p}$-value \\
\hline Mean Age(Years) $\pm \mathrm{SD}$ & $45.88 \pm 16.77$ & $52.30 \pm 13.73$ & $0.271, \mathrm{NS}$ \\
\hline Mean Zung Score & $61.47 \pm 3.95$ & $56.30 \pm 3.79$ & $0.001, \mathrm{~S}$ \\
\hline $\begin{array}{l}\text { No of patients with } \\
\text { depression }\end{array}$ & $0(0 \%)$ & $1(3.33 \%)$ & $0.69, \mathrm{NS}$ \\
\hline $\begin{array}{l}\text { Number of patients with } \\
\text { moderate depression }\end{array}$ & $13(76.47 \%)$ & $0(0 \%)$ & $0.000, \mathrm{~S}$ \\
\hline
\end{tabular}


Graph 2: Comparison of zung score in pre-dialysis and ESRD patients

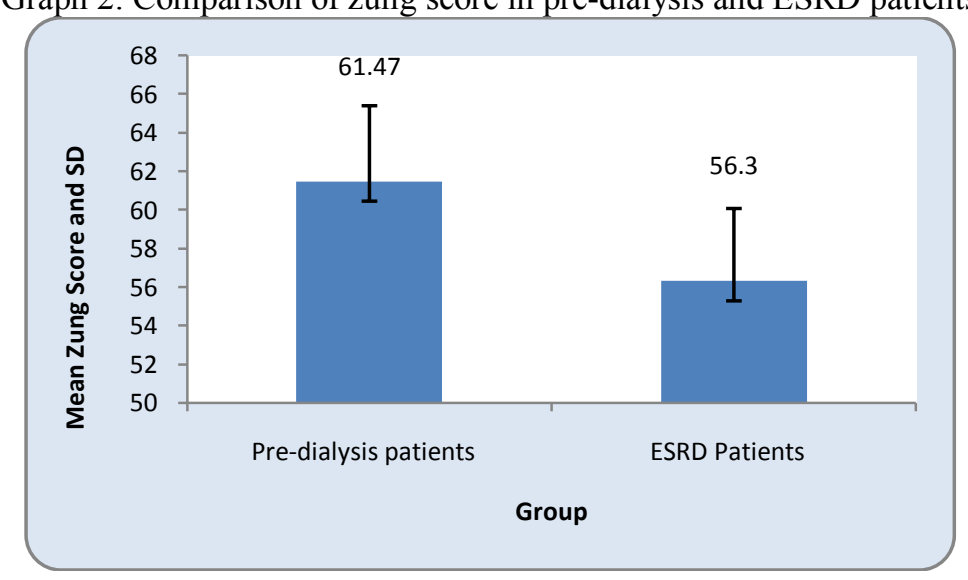

We again divided the CKD patients into end stage renal disease who are in dialysis treatment $(n=13) \&$ who are not on dialysis treatment $(\mathrm{n}=17)$. The demographic characters \& ZSDS (Zung self rating depression scale) in both groups were compared. The mean Zung score were significant in both the groups. Moderate depression was present in $43.33 \%$ patients who were not on dialysis.

The mean Zung score in pre-dialysis patient was $61.47 \pm 3.95$ versus ESRD patients on dialysis which was $56.30 \pm 3.79(\mathrm{P}<0.001)$ suggesting that depressive symptoms were more prevalent in CKD patients who were not on dialysis as compared to the patients on dialysis. The factors could be uremic symptoms \& other factors like poverty leading to inability to dialysis, financial burden for dialysis \& further management of CKD. Out of 17 patients on CKD who were on conservative management 13, patients $(76.47 \%)$ had moderate depression. No patients of dialysis group had moderate or severe depression; multiple regression analysis showed that no risk factor was incidentally contributing to depression.

Table 3: Multiple logistic regression showing the risk factors associated with depression

\begin{tabular}{|c|l|l|l|l|l|l|}
\hline \multicolumn{2}{|c|}{} & Coefficient & $\begin{array}{l}\text { Standard } \\
\text { Error }\end{array}$ & $\begin{array}{l}\text { Odd's } \\
\text { Ratio }\end{array}$ & F-value & p-value \\
\hline \multirow{3}{*}{} & Age(Yrs) & -0.00 & 0.06 & 0.030 & 0.146 & $0.885, \mathrm{NS}$ \\
\cline { 2 - 7 } & $\begin{array}{l}\text { CKD Duration } \\
\text { (months) }\end{array}$ & -0.02 & 0.07 & 0.075 & 0.376 & $0.710, \mathrm{NS}$ \\
\cline { 2 - 7 } & $\begin{array}{l}\text { Sex } \\
\text { (Male/Female) }\end{array}$ & -1.20 & 2.38 & 0.106 & 0.503 & $0.619, \mathrm{NS}$ \\
\cline { 2 - 7 } & Treatment & -1.49 & 2.15 & 0.151 & 0.696 & $0.493, \mathrm{NS}$ \\
\hline
\end{tabular}

\section{Discussion}

Depression is frequently seen in CKD patients. This can be due to a lot of contributory factors which can range from emotional reaction to the diagnosis \& natural course of disease. It's treatment modalities, as well as tremendous amount of losses experienced in terms of health, lifestyle, finances \& status of the patient.

This study was conducted in AVBR hospital which caters to the majority of CKD patients from central India as it is a tertiary, referral centre for CKD patents, being a rural hospital usually the CKD patients are pour \& have a lot of financial restrictions to afford the cost constrains of temporary \& permanent dialysis, CKD related drugs, travel cost etc. In our study, the frequency of depressive symptoms among patients with CKD was very high similar to some other studies. ${ }^{(6,7,8)}$

One study $^{(7)}$ using the Diagnostic \& Statistical Manual of Mental Disorders revised third edition (DSM THIRD) reported a prevalence of depression of $25 \%$ among patients of CKD on haemodialysis compared to the control, in contrast to our study in which we found that pre dialysis patients of CKD were more depressed as compared to their dialysis counterpart. We noted that depression was more as the CKD staged increased.

In our study the patients on dialysis were less depressed than the pre-dialysis CKD patients which differs from some other studies where no difference were found between the two groups. ${ }^{(9,10,11)}$ Different scales/ instruments used for the assessment of depression in other studies may account for this difference. The possible reason for more depression in pre-dialysis patients may be the complete inability to afford hemodialysis all together because of extreme poverty in this region of central India. There may be also marital conflicts, strained interpersonal relationship \& risk of job losses.

The effect of depression \& survival has not yet been scientifically clarified. Few studies have not shown any association between depression scores and outcomes. ${ }^{(12,13)}$ But some studies have confirmed that 
depression impacts negatively on survival. ${ }^{(6,14)}$ It also negatively affects the quality of life. ${ }^{(14)}$ The mechanism could be nin-compliance with medication \& unaffordability for dialysis, poor nutrition \& response from dysregulation of cytokines leading to worsened pathophysiology of patients as in our study.

Despite of high prevalence of depression in CKD patients, unfortunately very few are diagnosed \& are treated for the same. ${ }^{(3)}$ Reason for this may be lack of concern of the treating physician /nephrologist for the depressive symptoms concentrating more on the treatment part (drugs, dialysis) not caring for the emotional part.

Lack of carefully planned Randomised Control Trial (RCT) evaluating the efficacy \& safety of antidepression in this population of patients can be another explanation for the same. It is important to treat depression among CKD patients because of negative impact on the quality of life. Cognitive Behavioural Therapy (CBT) has been recognised as an effective psychological treatment for mild to moderate depression. ${ }^{(15)}$ Antidepressant medication like serotonin reuptake inhibitors(SSRT) \& psychotherapy can be an optimal form of therapy.

Further research, using this instrument \& further studies carrying out comparative analysis of prevalence \& depression among patients with chronic kidney disorder \& other chronic medical disorders are mandatory to assess the actual \& factual impact of depression on these chronic illness.

To conclude depression is a major accompaniment of CKD which should be given equal priority while treating such cases.

\section{Reference}

[1]. Kimmel PL,Levy NB, Psychology and rehabilitation. In:Daugirdas JT, Blake PG, Ing TS, editor. Handbook of diaysis, $3^{\text {rd }}$ ed. Philadelphia: Lippincott Williams and Wilkins 2001;413-419.

[2]. Hedayati SS, Finkelstein FO. Epidemiology, diagnosis and management of depressionin patients with CKD.Am J Kidney Dis 2009;54:741-52.

[3]. Kimmel PL,Peterson RA. Depression in patients with end-stage renal disease treated with dialysis:Has the time to treat arrived. Clin J Am Soc Nephrol 2006;I:349-52.

[4]. Watnick S,Kirwin P,Mahnensmith R,Concato J. The prevalence and treatment of depression among patients starting dialysis. Am J Kidney Dis 2003,41:105-10.

[5]. Zung WW.A self rating depression scale in an outpatient clinic. Arch Gen Psychiatry 1965;13:508-15.

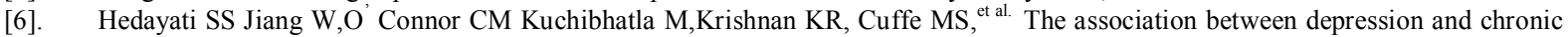
kidney disease and mortality among patients hospitalizes with congestive heart failure. Am J Kidney Dis2004;44:207-15.

[7]. Aghanwa HS, Morakinyo O.Psychiatry complications of haemodialysis at a kidney centre in Nigeria. J psychosom Res 1997;42:445-51.

[8]. Watnick S, Wang PL, Demadura T, Ganzini L. Validation of 2 depression,screening tools for dialysis patients.Am J Kidney Dis 2005;46:919-24.

[9]. Hedayati SS, Minhajuddin AT,Toto RD,Morris DW,Rush AJ.Prevalence of major depressive episode in CKD.Am J Kidney Dis $2009, ; 54: 424-32$.

[10]. Abdel-Kader K,Unruh ML, Weisbord SD. Symptoms burdern, depression and quality of life in chronic and end-stage kidney disease.Clin J Am Soc Nephrol 2009;4:1057-64.

[11]. Hedayati SS,Minhajuddin AT, Toto RD,Morris DW, Rush AJ.Validation of depression screening scales in patients with CKD. Am J Kidney Dis 2009;54:433-9.

[12]. Devins GM,Mann J,Mandin H.Psychological predictors of survival in end-stage renal disease.J Nerv Ment Dis 1990;178:127-33.

[13]. Christensen AJ,Wiebe JS,Smith TW,Turner CW. Predictors of survival among hemodialysis patients:Effect of perceived family support. Health psycho 1997;13:521-5.

[14]. Boulware LE,LiuY,Fink NE,Coresh J,Ford DE,Klag MJ ${ }^{\text {et al }}$. Temporal relation among depression symotoms, cardiovascular disease events,and mortality in end stage renal disease:contribution of reverse casuality. Clin J Am Soc Nephrol2006;1:496-504.

[15]. Cruz LN,de Almeida Fleck MP,Polanczyk CA. Depression as a determinant of quality of life in patients with chronic disease:Data from Brazil.Soc Psychiatry Psychiatr Epidermiol2010;45:953-61. 